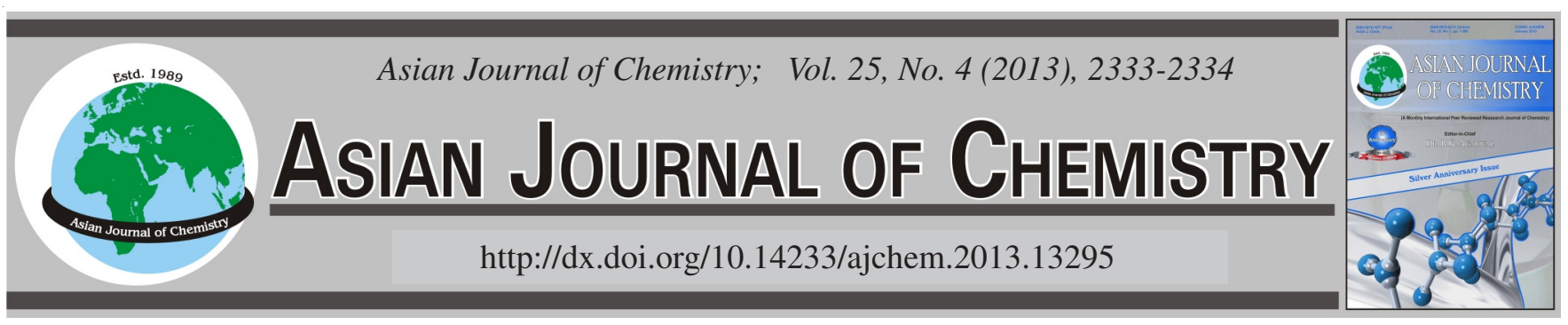

NOTE

\title{
Soap Stock Separation Process
}

\author{
Yousef FAZli $^{1, *}$, MaJid TAJdARI $^{2}$ and PARISA Kermani ${ }^{1}$
}

${ }^{1}$ Department of Chemistry, Faculty of Science, Arak Branch, Islamic Azad University, Arak, Iran

${ }^{2}$ Department of Chemical Engineering, Faculty of Engineering, Arak Branch, Islamic Azad University, Arak, Iran

*Corresponding author: Fax: +98 861 3670017; Tel: +98 861 3670017; E-mail: y-fazli@iau-arak.ac.ir; yousef.fazli@gmail.com

(Received: 20 December 2011;

Accepted: 26 October 2012)

AJC-12347

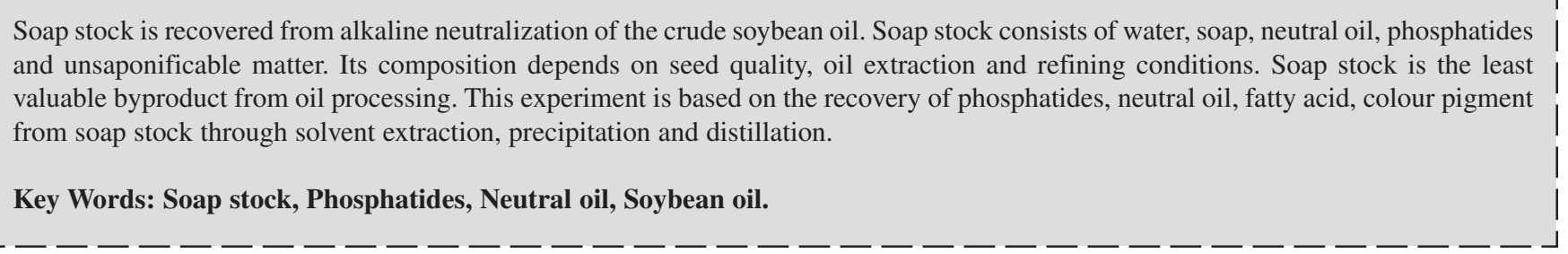

The primary constituents in crude fats and oils are triglycerides, but they also contain varying amounts of minor components, many of which significantly affect their chemical and physical properties. Exclusive of free fatty acids, crude vegetable oils commonly contain $2 \%$ or more nonglyceride substances. These minor components, referred to as the unsaponifiable fraction, consist of phosphatides, tocopherols, sterols, resins, carbohydrates, pesticides, proteins, trace metals and pigments, such as gossypol, carotene and chlorophyll. Some, but not all, of the nonglyceride materials are undesirable, therefore, the objective in all edible oil processing is to remove the objectionable impurities with the least possible damage to desirable constituents ${ }^{1}$.

(1) Phospholipids; (2) Pigments; (3) Pesticides; (4) Trace metals

Soapstock is recovered from alkaline neutralization of the crude or degummed soybean oil. Soapstock consists of water, free fatty acids, neutral oil, hydrolyzed phosphatides, unsaponifiable matter, proteins and mucilaginous substances. Its composition depends on seed quality and oil extraction and refining conditions. Soapstock is the least valuable byproduct from oil processing and it is generated at a rate of about $6 \%$ of the volume of crude soybean oil refined ${ }^{2}$. Free fatty acids are the most valuable components that can be recovered from soapstock. Usually, soapstock is returned to the oilseed meal to increase its lipid content as well as the weight. For use in feed, the soapstock must be reasonably free of pesticide residues. Acidulation with sulfuric acid stabilizes soapstock and also reduces the weight of the material to be handled.
Acidulated: Acidulated soybean soapstock is the product obtained from complete acidulation and thorough setting of soapstock, which itself is the by-product obtained from alkali refining of soybean oil.

Esterification: Esters can be made from acids (or related acyl derivatives) or from esters. Methyl esters for use as biofuel have been prepared from soapstock which is an abundant by-product of alkali refining.

Soap: Raw or acidulated soapstock could be used to manufacture soap directly or subjected to distillation and hydrogenation to obtain fatty acids for soap making. Soybean soapstock that have high levels of unsaturation and pigmentation are suitable for medium grade soaps for industrial purposes $^{3}$.

The gums isolated with an acid degumming process are not suitable for standard lecithin because their Phosphatide composition differs from those obtained with water degumming (higher phosphatidic acid) and they contain the degumming $\operatorname{acid}^{4}$.

Acetone, glycerol, phosphoric acid, hexane, hydrochloric acid (fuming $37 \%$ ) and sodium sulfate (anhydrous pure) were supplied by Merck (Darmsdat, Germany). Filter paper (Whatman 91) was obtained from Whatman International Ltd. (Maidstone, England). Soybean oil and Soybean Soapstock were supplied Famous Company (Tehran, Iran).

Acidity: The amount of free fatty acid was determined by ISO 660:1996

Colour: The colour was determined by Lavibond PFX $990^{5}$. 
$\boldsymbol{\beta}$-Carotene purity: The purity of $\beta$-carotene was determined with Allied Industrial Grop. Ltd., Altratone 30 PCT OS.

Soya soapstock specification is according to below table:

\begin{tabular}{ll}
\hline Unsaponifiable matter & $2 \%$ \\
\hline Moisture & $32 \%$ \\
Phosphatide & $2 \%$ \\
Total Fatty acid content & $40-33 \%$ \\
Beta-carotene & $130 \mathrm{ppm}$ \\
\hline
\end{tabular}

Acetone was added to the soapstock. Sediments, after complete mixing, were separated by filter paper. After washing with acetone for several times (so that colour of acetone does not change) sediments were dried in oven.

Acetone solutions separated from the previous step, was evaporated. So that separated solution volume was dropped to about $150 \mathrm{cc}$. After neutralization, the mixture was settled in oven. The oil phase will be separated from water phase and get specification below:

\begin{tabular}{|c|c|c|c|c|c|c|}
\hline \multirow[b]{2}{*}{ Characteristics } & \multicolumn{2}{|c|}{ Colour } & \multicolumn{2}{|c|}{ Chlorophyll } & \multirow[b]{2}{*}{$\begin{array}{c}\beta \text {-carotene } \\
(\mathrm{ppm})\end{array}$} & \multirow[b]{2}{*}{ Acidity } \\
\hline & Red & Yellow & $\begin{array}{c}\mathrm{A} \\
(\mathrm{ppm})\end{array}$ & $\begin{array}{c}\mathrm{B} \\
(\mathrm{ppm})\end{array}$ & & \\
\hline Cell $1 \mathrm{~cm}$ & 11.5 & 70 & 4.33 & Zero & 134 & $2.4 \%$ \\
\hline
\end{tabular}

Sediments isolated was solved in distilled water. The $\mathrm{pH}$ of the solution was adjusted to 3 . In these circumstances the oil and water phases separation were completed. Then the oil phase was separated completely by hexane extraction. The obtained oil phase characteristics are as follow:

\begin{tabular}{|c|c|c|}
\hline Characteristics & Acidity & Phosphatides \\
\hline Oily phase & $85.8 \%$ & $2.1 \%$ \\
\hline
\end{tabular}

In this phase, oily phase obtained in step 1 , will be saponified by adding $\mathrm{NaOH}$. After separation and drying of soap, $\beta$-carotene was extracted by hexane. Purity of $\beta$-carotene was $19500 \mathrm{ppm}$, which compare to amount on oil phase step 1 (134 ppm) is concentrated 145 times.

Therefore separation in all steps is as follow:

\begin{tabular}{|c|c|c|c|c|c|}
\hline \multicolumn{6}{|c|}{ Soapstock } \\
\hline \multicolumn{2}{|c|}{ Acetone residue $51 \%$} & \multicolumn{3}{|c|}{ Oily phase $17 \%$} & \multirow[b]{2}{*}{$\begin{array}{c}\text { Moist } \\
\text { ure } 32 \\
\%\end{array}$} \\
\hline $\begin{array}{c}\text { Fatty acid } 33.4 \\
\% \text { separsted } \\
\text { (Purity } 85.5 \% \text { ) }\end{array}$ & $\begin{array}{c}\text { Phosp- } \\
\text { hatide } 2 \%\end{array}$ & $\begin{array}{c}\beta \text {-carotene } \\
1.5 \% \text { (Purity } \\
1.95 \% \text { ) }\end{array}$ & $\begin{array}{c}\text { Fatty } \\
\text { acid } \\
0.41 \%\end{array}$ & $\begin{array}{l}\text { Neutral } \\
\text { oil } 15 \%\end{array}$ & \\
\hline
\end{tabular}

\section{Conclusion}

Normally, soap stock is used to obtain acid oil with dark colour. Through this experiment, achieved oil get less colour equal to Soya oil and separated beta carotene can be used as a suitable colour for oils and margarines.

\section{REFERENCES}

1. R.D. O'Brien, Fats and Oils Formulating and Processing for Application, CRC press, pp. 8-13 (2003).

2. P. Golbitz, Soya and Oilseed Blue Book, Soyatech, Inc., Bar Harbor, Maine, (2000).

3. F. Shahidi, Bailey's Industrial Oil and Fat Products. Edible Oil \& Fat Products: Edible oils. John Wiley \& Sons, Inc, vol. 2, pp. 572-592 (2005).

4. A.J. Dijkstra, Degumming, Refining, Washing and Drying Fats and Oils, in Proceedings of the World Conference on Oilseed Technology and Utilization, Applewhite, T.H., ED., AOCS Press, Champaign, IL, p. 139 (1993)

5. Official Methods and Recommended Practices of the American Oil Chemists' Society, American Oil Chemists' Society, Champaign, USA, edn 5 (1998). 